\title{
La liturgia funeraria en la Catedral de Oviedo. El Libro de los estatutos y constituciones de la Sancta Iglesia de Oviedo, con el ceremonial y kalendario de sus fiestas antiguas.
}

\author{
Sonsoles GARCÍA GONZÁLEZ
}

Universidad de Oviedo

Recibido: 14-5-2013 / Aceptado: 27-6-2013

RESUMEN: Alfonso Marañón de Espinosa, arcediano de Tineo y miembro del cabildo de la catedral de Oviedo, fue el autor de El Libro de los estatutos y constituciones de la Sancta Iglesia de Oviedo, con el ceremonial y kalendario de sus fiestas antiguas, publicado en Salamanca en 1588. A partir de tres aspectos específicos de los que informa esta consueta: la celebración del día de Todos los Difuntos, los enterramientos y aniversarios por obispos, se tratará de conocer y estudiar las costumbres y espacios funerarios de la catedral de Oviedo durante la Edad Media.

Palabras clave: Liturgia, funeraria, enterramientos, consueta, catedral, Oviedo, Oficio de Difuntos,

ABSTRACT: Alfonso Marañón de Espinosa, archdeacon of Tineo and member of the Oviedo's cathedral chapter, was the writer of El Libro de los estatutos y constituciones de la Sancta Iglesia de Oviedo, con el ceremonial y kalendario de sus fiestas antiguas, published in Salamanca in 1588. This article will explore and study the customs and funerary spaces through the information given by the early modern book: the celebration of All Saints, the burial of bishops and their anniversaries in the cathedral of Oviedo.

Keywords: Liturgy, funerary, burials, cathedral, Oviedo, Mass for the Dead, Liturgy of the Dead

\section{INTRODUCCIÓN}

Alonso Marañón de Espinosa conoció la catedral en el siglo XVI, y fue a finales del mismo, concretamente en 1588 cuando publicó El libro de los estatutos y constituciones de la Sancta Iglesia de Oviedo, con el ceremonial y kalendario de sus fiestas antiguas, en Salamanca. En esta obra dedicada a recoger las costumbres de la sede, describió paso a paso diversas festividades que tenían lugar en la catedral ovetense, según el mismo autor recogidas "de manuscritos antiguos"1, así como los miembros del cabildo y las funciones que estos

\footnotetext{
${ }^{1}$ Habla en varias ocasiones del Libro Gothico, y hace referencia a la librería gothica que fue de Pelayo. A. MARAÑÓN DE ESPINOSA, Libro de las costumbres y constituciones de la Santa Iglesia de Oviedo, con el ceremonial y el kalendario de sus fiestas antiguas, Salamanca, 1588, B3.
} 
desempeñaban. Es evidente que se trata de una obra clave para el conocimiento de los usos catedralicios a principios de la edad moderna, pero también para un aspecto que hasta ahora ha pasado desapercibido, como lo son los espacios funerarios medievales que existieron en la catedral de Oviedo y que, en algunos casos, no se han conservado.

Marañón de Espinosa se recreó en la reproducción escrita de las celebraciones que se llevaban a cabo en la sede ovetense, explicando el tipo de exequias específico para los obispos, los aniversarios que se celebraban en la catedral y, especialmente, la celebración del día de Todos los Difuntos. A partir de la descripción de esta fiesta principal se intentará conocer un poco más del aspecto que tuvo la catedral de Oviedo en su etapa medieval, especialmente en lo que a sus espacios funerarios se refiere.

\section{EL LIBRO DE LOS ESTATUTOS Y CONSTI- TUCIONES DE LA SANCTA IGLESIA DE OVIEDO, CON EL CEREMONIAL Y KA- LENDARIO DE SUS FIESTAS ANTIGUAS.}

Alonso Marañón de Espinosa llegó a la sede ovetense con el nombramiento como obispo de su primo don Gonzalo de Solórzano, con quien había estudiado en el Colegio Mayor de Santiago en la Universidad de Salamanca. Según Risco, de él obtuvo el Arcedianato de Tineo, una ración y algunos beneficios, y desde este cargo comenzó a recopilar información sobre la diócesis ovetense. Una vez fallecido el prelado, Alonso Marañón de Espinosa redactó este ceremonial sobre la catedral de Oviedo durante el obispado de Diego Aponte de Quiñones, a quien dedica la obra.

La consueta comienza con la dedicatoria al obispo Aponte de Quiñones, seguida por la explicación de cómo Alonso Marañón de Espinosa llega a realizar este trabajo. Después de un breve repaso por la historia de la diócesis ovetense ${ }^{2}$, pasa a describir los estatutos y ceremonias que tenían lugar en la catedral. Este tipo de documentos de carácter litúrgico constituyen una importante fuente de información para la historia del arte, y en concreto de la arquitectura, en ocasiones desaparecida o muy reformada, si bien es necesario tener en cuenta una serie de aspectos importantes que ya fueron destacados por los pioneros en esta escuela historiográfica. Autores como Eric Palazzo ${ }^{3}$, con sus numerosos estudios acerca de la liturgia medieval, quien propone una metodología protagonizada por la relación entre arte y liturgia en la edad media, basándose en la antropología de los rituales litúrgicos medievales y sus manifestaciones artísticas e insistiendo en el objeto artístico como elementos funcionales y no meramente estéticos ${ }^{4}$. Una vez que entra en juego el término "ritual", es necesario tomarlo con precaución, ya que cuando las tendencias y métodos historiográficos se han entremezclado entre sí, se ha utilizado un vocabulario propiamente antropológico que en ocasiones no es posible extrapolar a todas los campos. Así aparecen una serie de investigadores que parten de la noción de ritual como un concepto antropológico y se dedican a exponer las razones por las cuales un ritual medieval no puede, precisamente, denominarse de ese modo, pues carece de

\footnotetext{
${ }^{2}$ En esta historia de la diócesis ovetense que utiliza a modo de introducción, se incluye un catálogo de obispos con informaciones fidedignas respecto al siglo $\mathrm{XVI}$, sin embargo hay que tomar con precaución las que se refieren a tiempos más remotos, que fueron directamente copiadas de manuscritos conservados en el archivo catedralicio como la defensa del origen de la sede ovetense en Lucus Asturum, inspirada en las obras de Pelayo de Oviedo.

${ }^{3}$ E. PALAZZO, Liturgie et société au Moyen Age, París, 2000; L'espace rituel et le sacré dans le christianisme : la liturgie de l'autel portatif dans l'Antiquité et au Moyen Âge, Turnhout, 2007.

${ }^{4}$ E. PALAZZO, "Art et Liturgie au Moyen Age. Nouvelles Approches Anthropologique et Epistémologique", en Anales de Historia del Arte, 2010, Volumen Extraordinario, 31-74.
} 
las características propias para que así sea ${ }^{5}$. Entre estos destacan Gerd Althoff ${ }^{6}$, Philippe Buc $^{7}$ y Jean Claude Schmitt ${ }^{8}$, en este último caso, cercano a este mundo del ritual como teórico de una construcción medieval como cultura gestual.

Aplicando estas precauciones, el estudio de la liturgia se convierte en una fuente muy abundante para informarnos, no solo de una forma de pensar y ver el mundo, es decir, como base para la historia de las mentalidades, también permite conocer la existencia de elementos artísticos que no se han conservado e incluso a veces llegar a plantear hipótesis sobre la apariencia de los mismos. Otras consuetas peninsulares, contemporáneas a la ovetense y que tratan temas similares han permitido a través de sus estudios conocer esos aspectos funerarios no

\footnotetext{
${ }^{5}$ El significado antropológico de ritual cuenta con la característica de la repetición de una serie de acciones siempre de la misma manera, en palabras de Gerd Althoff, "We talk about rituals when actions, or rather chains of actions, of a complex nature are repeated by actors in certain circumstances in the same or similar ways, and, if this happens deliberately, with the conscious goal of familiarity" (G. ALTHOFF, "The Variability of Rituals in the Middle Ages", en G. ALTHOFF, J. FRIED, y P. GEARY, Medieval Concepts of the Past. Ritual, Memory, Historiography, 2002, pág. 71). En el momento en que sabemos, a través de las fuentes directas, que eso que llamamos rituales medievales tienen un carácter de continuo cambio para ajustarse a una determinada situación llegando a realizarse incluso rupturas deliberadas de los mismos, estos historiadores se manifestarán en contra del uso del término "ritual" en lo que la Edad Media se refiere.

${ }^{6}$ G. ALTHOFF, "The Variability of Rituals in the Middle Ages", en G. ALTHOFF, J. FRIED, y P. GEARY, Medieval Concepts...pp. 71-87.

7 P. BUC, "Rituel politique et imaginaire politique au haut Moyen Âge", Revue historique 4/2001 (n 620), p. 843-883; “Text and Ritual in Ninth-Century Political Culture. Rome, 864" en Medieval Concepts...123-138; Dangereux rituel. De l'histoire médiévale aux sciences sociales, París, 2003; "The monster and the critics: a ritual reply" en Early Medieval Europe, 2007, 15. pp. 441-452.

8 J-C. SCHMITT, "Le suicide au Moyen Âge" en Annales, Économies, Societés, Civilisations. 31e année, nำ -1976, pp. 3-28; Le raison des gestes dans l'Occident Médiéval, Mayenne, 1990.
}

conservados, por ejemplo la consueta mallorquina de Font i Roig, de 15119, así como uno de los códices de la Pretiosa de la catedral de Lleida ${ }^{10}$.

Alonso Marañón dedica el primer capítulo propiamente dicho de su obra, a lo que aparece denominado como "officios", con la enumeración de todos los miembros del cabildo ovetense, sus funciones y las ganancias que obtenían por la realización de sus labores ${ }^{11}$. A continuación incluye un calendario propio de la Santa Iglesia Ovetense, donde aparecen los santos y fiestas a celebrar en ella, que describe inmediatamente ${ }^{12}$. Estas fiestas se dividían, según el decreto del concilio de Trento, en dobles, semidobles y simples ${ }^{13}$. Dentro de las dobles diferenciaban: fiestas principales, de canónigos antiguos, de cuatro capas y de dos capas, de las cuales la fiesta de Todos los Santos que se analizará a continuación se engloba en las principales. Por último, describe las funciones de lugares e instituciones pertenecientes a la iglesia ovetense, para acabar con la declaración y aprobación de los estatutos ${ }^{14}$.

En relación a costumbres funerarias y espacios de enterramiento en la diócesis ovetense, Alonso Marañón de Espinosa explica tres aspectos que resultan interesantes: destaca una fastuosa celebración del día de

\footnotetext{
${ }^{9}$ A. PONS CORTÉS, “La tomba de Jaume II a la Seu de Mallorca i el seu cerimonial de la festivitat del Día dels Morts", en La ciutat de Mallorca i els segles del gòtic. XXVIII Jornades d'estudis històrics locals, Palma, 2010, pp. 245-265.
}

10 F. CASTILLÓN CORTADA, "Liturgia funeral en el claustro de la Seu Vella de Lleida", en en LORÉS, Inma; VILÀ, Frederic, Congres de la Seu Vella de Lleida (Actes), 6-9 març 1991, 1991, pp. 225-231.

11 A. MARAÑÓN DE ESPINOSA, Libro de las costumbres...1-44v.

12 A. MARAÑÓN DE ESPINOSA, Libro de las costumbres...sin paginar, entre las páginas 44 y 53 .

13 A. MARAÑÓN DE ESPINOSA, Libro de las costumbres...53-128v.

${ }^{14}$ A. MARAÑÓN DE ESPINOSA, Libro de las costumbres...129-185. 
Todos los Difuntos, acompañada por la descripción del tipo de exequias para prelados, diferentes de las del resto de dignidades, asi como la relación de los distintos aniversarios que aún en el XVI se celebraban en la catedral de Oviedo.

\section{LA FIESTA DE TODOS LOS DIFUNTOS Y SU CELEBRACIÓN COMO FIESTA PRIN- CIPAL EN LA CATEDRAL DE OVIEDO}

Desde los inicios de la cristiandad la recitación del nombre del fallecido se utilizaba en la celebración eucarística como una especie de ofrenda, probablemente con algún carácter pagano residual ${ }^{15}$. A partir del siglo VI comienza a extenderse la idea de la existencia de un estado intermedio entre el cielo y el infierno, desarrollándose una noción de la misa como estrategia intercesora ${ }^{16}$. Así, a partir de los Diálogos de Gregorio I se realizan una serie de modificaciones en cuanto a la relación entre vivos y muertos: para empezar, las fórmulas de la misa romana por los fallecidos fueron revisadas para la creación de la misa en conmemoración por los difuntos, incorporada al sacramentario gelasiano. Además, se introdujo la idea de que para la salvación del alma del fallecido resultaba útil, en función del pecado, el enterramiento apud ecclesia ${ }^{17}$. También a Gregorio Magno se le atribuye la introducción de la eficacia de la oración por los muertos así como del Trental, las series de treinta misas intercesoras ${ }^{18}$.

\footnotetext{
15 F. PAXTON, Christianizing Death. The creation of a ritual process in early medieval Europe, Ithaca and London, 1990, pág. 66.
}

16 M. LAUWERS, La mémoire des ancêtres, le souci des morts Morts, rites et societé au moyen âge (diocèse de Liège, XI-XIII siècles), "Théologie Historique", no 103, 1997, pág. 93. La forma de intercesión era la recitación de nombres en un momento concreto de la eucaristía, un memento de los muertos que ya fue introducido por el papa Gelasio (492-496) en el canon de la misa.

17 M. LAUWERS, La mémoire des ancêtres pp. 85-87.

18 F. PAXTON, Christianizing Death..., pp. 66-69; S. ROFFEY, Chantry Chapels and Medieval Strategies for the
Este tipo de estrategias fueron calando en la mentalidad de la época como una forma de facilitar la salvación; entre los siglos VIII y X, con la dinastía carolingia ejerciendo un poder imperial en un importante espacio del territorio europeo occidental, tuvo lugar la expansión del oficio de difuntos y la fundación de misas privadas ${ }^{19}$, que sustituyeron al memento gelasiano y su recitación de listas de nombres, por un memento de carácter colectivo ${ }^{20}$. Philippe Ariès consideró como claves esos siglos IX y X para la expansión de la preocupación en torno a la muerte, generando numerosos cambios, hasta el punto de que después de Carlomagno, las misas acaban por convertirse en misas de muertos ${ }^{21}$.

Estas misas por los difuntos obtuvieron gran importancia en la compleja religiosidad irlandesa y de las islas, donde parece que tiene lugar el origen de la idea de vincular un pecado con una penitencia correspondiente, de tal manera que aquellos pecados que no llegan a ser purgados en vida, deben serlo después de la muerte con la ayuda de los vivos ${ }^{22}$. Esta ayuda de los vivos para alcanzar un estado de gracia en la muerte se lleva a cabo a través de la contratación de misas votivas, el ofrecimiento de una misa en nombre de determinada persona fallecida por la que se lleva a cabo un pago, y así se convierten las relaciones entre vivos y muertos en un intercambio económico ${ }^{23}$. Otro ejemplo que es resultado

Afterlife, 2008, pág. 34.

${ }^{19}$ El oficio de difuntos se conforma en este momento como un conjunto de oraciones y textos recitados regularmente por las comunidades eclesiásticas en diferentes horas litúrgicas, que tendrá amplia extensión a nivel europeo.

${ }^{20}$ M. LAUWERS, La mémoire des ancêtres pp. 90-100.

${ }^{21}$ P. ARIÈS, El hombre ante la muerte, Madrid, 1983, pp. 132-135.

22 F. PAXTON, Christianizing Death...pp. 66-69.

${ }^{23}$ P. GEARY, "Interaction between the living and the dead", en Living with the dead in the Middle Ages, 1994, pp. 77-92. Patrick Geary explica como las relaciones se 
de esta nueva concepción entorno a la muerte y la purgación de los pecados una vez muerto, es la aparición de confraternidades de rezadores por los muertos; asociaciones de voluntarios que realizaban servicios litúrgicos ante la muerte de sus miembros, y que llegaron a generar unas listas de nombres que circulaban entre monasterios buscando la multiplicación de las oraciones ${ }^{24}$. Para el siglo $\mathrm{X}$, el canto diario del oficio de muertos por los hermanos era de carácter universal en el monacato benedictino ${ }^{25}$; las grandes abadías carolingias realizaban este tipo de conmemoraciones generales por todos los difuntos de la parroquia al principio de cada mes, y además realizaban otra de carácter anual por todos los hermanos difuntos, cuya fecha variaba en función del centro ${ }^{26}$.

Finalmente, las diversas conmemoraciones que evolucionaban paralelamente de forma local, acabaron por institucionalizarse en 1030, cuando en Cluny ocupaba el cargo de abad Odilon, se instituyó la conmemoración solemne de todos los difuntos el 2 de noviembre ${ }^{27}$. La institución de la fiesta de Todos los Difuntos cuenta con una leyenda de fundación, según la cual, un peregrino que volvía de Tierra Santa se detuvo a descansar en una ermita (cuya ubicación varía según la fuente), y allí le fue revelado que las almas de los pecadores reclamaban las oraciones de la comunidad cluniacense, encargando al peregrino que comunicara el mensaje al abad ${ }^{28}$. Poco tiempo después fue aprobada por el papa León IX y se produjo una veloz difusión por las iglesias del occidente europeo.

resumen en un intercambio económico de manera que el vivo al heredar acepta el compromiso de mantener viva la memoria del fallecido.

${ }^{24}$ F. PAXTON, Christianizing Death...pp. 98-102.

${ }^{25}$ F. PAXTON, Christianizing Death...pp. 134-138. A finales del VIII en Montecasino los hermanos fallecidos eran recordados diariamente; en Fulda dos veces diarias.

${ }^{26}$ M. LAUWERS, La mémoire des ancêtres pp. 144-145

${ }^{27}$ M. LAUWERS, La mémoire des ancêtres...pp. 140-141.

${ }^{28}$ M. LAUWERS, La mémoire des ancêtres...pp. 145-146.
En la catedral ovetense que conoce Alonso Marañón se celebraba una fiesta principal que estaba compuesta por una larga procesión que incluye el templo, la capilla del Rey Casto, la capilla de don Gutierre, el claustro y la capilla mayor, recorriendo así todos los espacios funerarios catedralicios, $\mathrm{e}$ incluía además misa y ofrenda, con una duración de al menos dos días (fig. $1{ }^{29}$.

De la sacristía salían cuatro caperos, con capas negras y cetros blancos; el capellán del obispo con ropas negras; dos acólitos con candeleros y velas; quienes al finalizar las segundas vísperas de la fiesta se dirigían al coro donde entonaban las vísperas de difuntos. Estas dignidades, acabadas las vísperas, regresaban a la sacristía a devolver sus capas mientras se decían las Completas. Una vez acabadas estas, el Canónigo que hubiera entonado las Completas, comenzaba la procesión a Rey Casto mientras entonaba la salve, acompañado por dos acólitos, delante, con sus candeleros y entre ellos un mozo de coro que llevaba un libro con paño; cerraban la comitiva los mozos de coro y el preste. Llegados a la sacristía se les unen los caperos y el capellán que habían vuelto antes a la sacristía, donde todos entraban a ponerse capas negras.

La primera estación de la procesión tiene lugar en la capilla del Rey Casto (fig. 2), donde entran por el siguiente orden: el turiferario, con brasa y naveta de incienso; la cruz negra, con candeleros; un mozo de coro con caldero, agua bendita y aspersorio; y finalmente, los cuatro caperos, el preste, y el mozo de coro que porta el libro de oración. Terminada la salve comienza un primer responso, llevado a cabo por los caperos, mientras las tumbas de los reyes, que están cubiertas por un dosel de terciopelo negro, y acompañadas por dos candeleros de plata con las velas encendidas, reciben el agua bendita y el incienso. Este proceso de bendición e incensión de

${ }^{29}$ A. MARAÑÓN DE ESPINOSA, Libro de las costumbres...108v-111. 
sepulturas se repite en cada una de las diez estaciones que se llevan a cabo a lo largo de la procesión.

Es en la misma capilla del Rey Casto donde comienza el segundo responso, con el que salen al crucero del templo. La siguiente estación tiene lugar en la nave de Santa Catalina, si bien no contiene más ceremonial que los responsos, al igual que sucede con la estación del trascoro, donde han empezado ya el quinto. Mientras tiene lugar ese quinto responso, la procesión continúa su camino a la nave de la capilla de don Gutierre, en cuyo interior tiene lugar la cuarta estación para realizar una oración en torno al sepulcro episcopal, a cuyos pies se colocaban para la ocasión, la cruz y los candeleros que llevaba la procesión.

Desde la capilla de don Gutierre, y acompañados por el sexto responso se dirigían a la que era la primera estación del claustro, a mano derecha ${ }^{30}$; la procesión recorría las cuatro pandas claustrales en dirección contraria a la de las agujas del reloj, mientras se recitan hasta el noveno responso, que tiene lugar en la cuarta y última estación del claustro, en la panda norte, donde se encontraba el altar de Belén (fig. 3).

Una vez que la procesión ha salido del claustro se detiene por última vez, "entre las dos rejas" del coro y el altar mayor, en el entorno de lo que sería la sepultura del obispo Alonso de Palenzuela ${ }^{31}$. Allí tiene lugar la última estación, se entona el último responso, que se remata con varios kyries, versos del capellán del obispo y por último, los caperos piden por los fallecidos un descanso pacífico, con los candeleros y la cruz apoyados en la grada más baja del altar mayor.

\footnotetext{
30 “Hacen estación en la primera estación del claustro, a mano derecha", se entiende, desde la entrada de la catedral hacia el claustro. A. MARAÑÓN DE ESPINOSA, Libro de las costumbres y constituciones... pág. 110.

31 S. GARCÍA GONZÁLEZ, Arte y liturgia funeraria en la catedral de Oviedo. Los enterramientos episcopales, Tesina de Licenciatura Inédita, Universidad de Oviedo, 2011, pág. 56.
}

Este tipo de procesiones que recorren los espacios funerarios catedralicios aparecen documentados en otros templos hispánicos, como es el caso de la catedral de Pamplona ${ }^{32}$, y probablemente el de Toledo, donde el ceremonial de Todos los Difuntos se celebra como fiesta mayor del ciclo litúrgico de seis capas incluiría probablemente una procesión similar a la ovetense, si bien existen muy pocas noticias ${ }^{33}$.

Al día siguiente de la conmemoración de los difuntos, se repite una vez más la procesión descrita, con sus respectivos responsos y oraciones. Una vez acabada, las dignidades se disponen a comenzar la misa pro defunctis al final de la cual tiene lugar el ofertorio: el preste, el diácono y el subdiácono bajan las escaleras del altar mayor para recibir las ofrendas de las mujeres de la parroquia, que aportan pan y vino sobre las sepulturas $^{34}$, y una vela a la iglesia catedral que le ofrecen al sacerdote tras haber besado su mano ${ }^{35}$.

Estas aportaciones de ofrendas en forma de pan y vino parece que podrían estar relacionados con los propios banquetes funerarios que tenían lugar en las casas de la familia del fallecido tras su funeral ${ }^{36}$, y en ellas se perciben claras resonancias de las comidas rituales propias

32 S. HIDALGO SÁNCHEZ, "El claustro, un espacio polifuncional: El caso de la catedral de Pamplona (Navarra)", en Intus-Legere Historia, año 2010, vol. 4, ำ1, pp. 63-91.

33 M.J. LOP OTÍN, “La catedral de Toledo, escenario de la fiesta bajomedieval", en P. MARTINEZ-BURGOS GARCÍA, y A. RODRIGUEZ GONZALEZ (coords.), La fiesta en el mundo hispánico, Cuenca, 2004, pp. 213-243.

${ }^{34}$ El pan y el vino no solo eran una rememoración del sacrificio de Jesucristo, eran así mismo, desde la temprana Edad Media, es el sustento más común entre los cristianos. A. MCGOWAN, Ascetic Eucharists, Food and Drink in early christian ritual meals, Oxford, 1999, pp. 91-95

35 A. MARAÑÓN DE ESPINOSA, Libro de las costumbres y constituciones...pp. $110 \mathrm{r}$ y $111 \mathrm{v}$.

36 S. ROYER DE CARDINAL, Morir en España (Castilla Baja Edad Media), Buenos Aires, 1992, pp. 154-156. 
de la Antigüedad grecorromana ${ }^{37}$. Se ha comprobado que este tipo de ofrendas en las sepulturas de los difuntos perduraron en diversas comarcas pirenaicas, especialmente en ocasión de los entierros y misas por las ánimas ${ }^{38}$ : existen prohibiciones sinodales tan tardías como la de Mondoñedo de 1541, que condena esta costumbre ${ }^{39}$. En el contexto catedralicio estas prácticas pueden relacionarse con otros ejemplos, como la ya nombrada consueta de la catedral de Mallorca, donde con ocasión del día de los difuntos se realizaba una ofrenda de pan a los pobres delante de las tumbas ${ }^{40}$. En el caso ovetense, la consueta no llega a informar acerca de qué sucedía con las ofrendas realizadas el día de Todos los Difuntos, aunque comparando esta actividad con el resto de la península, resulta lógico pensar que se repartiría entre los pobres ${ }^{41}$.

${ }^{37}$ F.J. FERNANDEZ CONDE, La religiosidad medieval en España. I Alta Edad Media (siglos VII-X), Oviedo, 2000, pp. 519.

38 F.J. FERNANDEZ CONDE, La religiosidad...pág. 520. El autor del libro comprueba estos hechos para el país vasco francés y las comarcas pirenaicas, sin embargo esta consueta extendería la costumbre hasta al menos la comunidad asturiana.

39 F.J. FERNANDEZ CONDE, La religiosidad...pág. 521. "En los mortuorios que hacen y el día de los finados, que es otro día de todos los santos, comen y beven y ponen mesas dentro de las iglesias, y lo que es peor, ponen jarros y platos encima de los altares, haciendo aparador de ellos".

${ }^{40}$ A. PONS CORTES, “La tomba...”, pág. 252

${ }^{41}$ La catedral de Oviedo conserva en la crujía sur del claustro una puerta denominada de la limosna, abierta en el siglo XVIII cuando se edificó el claustro alto, sin embargo puede hacer alusión a una tradición de reparto de limosnas entre los pobres más antigua. E. CARRERO SANTAMARÍA, El conjunto catedralicio de Oviedo durante la Edad Media, Oviedo, 2003, pp. 91-92. Este tipo de limosnas son comunes en las sedes castellanas, así por ejemplo, en la catedral de Toledo, la puerta del claustro que como en caso ovetense da al palacio episcopal y donde se otorga esta limosna se denomina puerta del mollete, mientras en las catedrales de la corona de Aragón aparece como institucionalizada esta costumbre recibiendo el nombre de almoina. G. FERNÁNDEZ SOMOZA, “Iconografía y funcionalidad arquitectónica en la pintura de las limosnas catedralicias en la corona de

\section{ANIVERSARIAS DE OBISPOS ${ }^{42}$}

La catedral de Oviedo albergaba tres tipos de aniversaria diferentes, unas eran cantadas, otras cantadas solemnes y las terceras, cantadas no solemnes. Las aniversarias por obispo se encuadran dentro de estas últimas, entre las que se enmarcan las celebradas por otras dignidades, y legos o personas fuera del cabildo, si bien también existían variaciones dentro de las aniversarias cantadas no solemnes en función de la dignidad del fundador.

En el caso de este tipo de celebraciones por el alma de los obispos, se comenzaban las antífonas por dos mozos de coro, y la misa y oración era dicha por el capellán mayor del obispo, que comenzaba el primero de los responsos en su silla alta. Las lectiones que tienen lugar durante el nocturno eran llevadas a cabo por tres dignidades, dos del coro de la tabla ${ }^{43}, y$ una del otro coro. Llegado el segundo responso, este se decía por un canónigo, y la respuesta en verso por dos mozos de coro. El tercero de los responsos lo realizaba un canónigo del coro de la tabla, quien también decía los versos y comenzaba el kyrie desde su silla. Finalmente, en las laudes, el primer verso de un aniversario de obispo era dicho por dos canónigos antiguos, y el segundo por dos canónigos modernos. Mientras se celebraban estos aniversarios, se colocaba a la entrada del coro, detrás del Facistol, candelabros con candelas encendidas.

Aragón", en E. CARRERO SANTAMARÍA, y D. RICO CAMPS, Catedral y ciudad medieval en la Península Ibérica, Murcia, 2005, pp. 77-97.

${ }^{42}$ A. MARAÑÓN DE ESPINOSA, Libro de las costumbres y constituciones...pp. 111-115.

43 A. MARAÑÓN DE ESPINOSA, Libro de las costumbres y constituciones...pp. 135. La tabla era realizada por el sochantre, y leida por el mismo todos los sábados después de la preciosa, escrita en latín incluía las obligaciones de las dignidades y lo que por ellas recibían. Una vez acabada de leer, se situaba durante la semana en el ángulo alto del coro, para que pudiera ser consultada. 


\section{ENTIERRO Y OFICIOS POR PRELADO}

El ceremonial ordena en estas ocasiones la organización de una procesión que comienza en la catedral, y está formada por varias dignidades del cabildo catedralicio: el capellán mayor, que viste amicto, alba, estola y capa; el diácono y subdiácono, ambos con el hábito de su orden; dos acólitos con candeleros y velas, y otros dos, uno con el agua bendita y otro con el libro de la oración, además de un sacristán que porta la cruz, todos vestidos con dalmáticas negras; y por último, tres caperos, con capas negras y cetros blancos.

Una vez llegados al lugar donde se encuentra el cuerpo del prelado, comienza el ceremonial con un responso con su oración, seguido del besamanos al difunto obispo por orden de antigüedad entre las dignidades. Mientras los criados del obispo trasladan el cuerpo a la puerta de la iglesia, las dignidades lo acompañan con otro responso; desde esa puerta, las dignidades lo transportaban a un estrado entre las dos rejas, y a sus pies la cruz y los candeleros, es decir, en el espacio que se encontraba entre el altar mayor y el coro de los canónigos ${ }^{44}$.

Ya situadas las dignidades en el coro, daba comienzo una misa cantada, protagonizada por la lucha de coros entre unas y otras dignidades. Mientras esto sucede, otros dicen de forma rezada; nocturnes y laudes. Acabada la misa, todas las dignidades se sitúan en el entorno del cadáver para decir cuatro responsos y cuatro oraciones con sus correspondientes bendiciones por aspersión e incienso, terminando con Requiescant in pace, Amen, y procediendo al entierro del prelado. Si el entierro se produce en la catedral, y Alonso de Marañón de Espinosa; lo da por hecho,

\footnotetext{
${ }^{44}$ Respecto a la definición espacial y terminológica de las estructuras corales ver E. CARRERO SANTAMARÍA, "Centro y periferia en la ordenación de espacios litúrgicos: las estructuras corales", en Hortus Artium Medievalium, 14, 2008, pp.
}

el cuerpo es transportado por cuatro dignidades a la sepultura ${ }^{45}$.

Estos elaborados funerales dedicados a los obispos de la sede no terminan en el mismo día, sino que se prolongan hasta el tercero, terminando con el responso de absolución. A la manera que fue realizada la misa de funeral, debe realizarse la misa de "tercero día" y de cabo de año, excepto que el responso final, que tendría lugar en el entorno del enterramiento, solo debe ser uno, en lugar de varios. El hecho de que el prelado sea protagonista de las misas durante tres días nos da una clara visión de la importancia de su fallecimiento, sin olvidar el significado de esa duración.

Estas misas y oraciones por el alma del difunto se acompañaban por una serie de ofrendas y disposiciones de carácter físico que son las siguientes: en el entierro, oficios, misa de tercer día y de cabo de año, debe haber dieciséis hachas de cera, además de tres doblados de cera. Durante los oficios, entre el día del funeral y el tercer día, deben ofrecerse doce anegas de pan en grano y tres pichetes de vino diario, que permanecen en la capilla mayor hasta el tercer día. Además de esta ofrenda, en las misas de entierro, tercer día y cabo de año, se realiza otra compuesta de pan cocido, vino y compango.

Alonso Marañón de Espinosa no solo nos transmite la forma de realización de estas misas de entierro y sus ofrendas, sino que no se olvida del pago que había de

\footnotetext{
${ }^{45}$ A. MARAÑÓN DE ESPINOSA, Libro de las costumbres y constituciones...pp. 119-120. Añade unos párrafos más adelante, cuando habla de la descripción de las misas de tercero día y de cabo de año, que se dicen los responsos en el entorno del túmulo, "que ha de estar hecho como suele por el prelado". En el caso de las comunidades cluniacenses, donde la excepción era el enterramiento dentro del templo, también era transportado por cuatro hermanos a su sepultura en el cementerio de los hermanos, donde la tumba era preparadas y bendecida por aspersión a la vez que el cadáver. M. CASSIDY-WELCH, Monastic Spaces and their meanings. Thirteenth-century english cistercian monasteries, Turnhout, 2001, pp. 229-232.
} 
realizarse a la mesa capitular por sus servicios, que era de quincemil maravedíes por los tres días de oficios, tres mil por la misa de tercer día y otros tres mil por la de cabo de $a n ̃ o^{46}$.

\section{LOS ESPACIOS FUNERARIOS EN LA CA- TEDRAL DE OVIEDO SEGÚN EL LIBRO DE LOS ESTATUTOS Y CONSTITUCIONES DE LA SANCTA IGLESIA DE OVIEDO, CON EL CEREMONIAL Y KALENDARIO DE SUS FIESTAS ANTIGUAS.}

El texto correspondiente a la procesión del día de los difuntos hace alusión a algunos de los espacios funerarios de carácter privilegiado más importantes que la catedral de Oviedo generó a lo largo de la Edad Media y aún conservaba en el siglo XVI: la capilla del Rey Casto, la capilla de don Gutierre, el claustro y la capilla mayor.

\section{Santa María del Rey Casto}

Cuando Marañón de Espinosa hace referencia a Rey Casto, este espacio aun se correspondía con la basílica exenta de Santa María, fundada por Alfonso II, desaparecida en el siglo XVIII ${ }^{47}$. Esta iglesia, localizada al Norte de San Salvador, se configuraba como un espacio contraabsidado destinado al enterramiento de los reyes asturianos y sus familiares ${ }^{48}$. Su tipología como espacio

46 A. MARAÑÓN DE ESPINOSA, Libro de las costumbres y constituciones...pp. 118-121. M. LAUWERS. La mémoire des ancêtres pp. 286-290. Lauwes interpreta los funerales de obispos como una ceremonia de representación de toda la sociedad medieval, una manera de redefinir la ordenación social, de dejar ver esas estructuras sociales a través del ritual funerario.

${ }^{47}$ V. DE LA MADRID ÁLVAREZ, “La construcción de la Capilla de Nuestra Señora del Rey Casto y Panteón Real de la Catedral de Oviedo", Liño, 9, 1990, pp. 77-108.

${ }^{48}$ R. ALONSO ALVAREZ, "Los enterramientos de los reyes de León y Castilla hasta Sancho IV", en e-Spania [online] , 3 I juin 2007, mis en ligne le 31 janvier 2008, Consulté le 28 avril 2013. URL : http://e-spania.revues. org/109; “El panteón de los reyes de Asturias: modelos funerario regio a los pies de una basílica pero separado de ella y con un único acceso interno, tal como describe Ambrosio de Morales $^{49}$, ha sido un elemento arquitectónico muy recurrente para tratar de explicar otros espacios funerarios occidentales en la edad media hispánica ${ }^{50}$.

Según las fuentes documentales, este panteón albergó los restos de Fruela I y su esposa, Alfonso II, Ramiro I y su esposa Urraca, Ordoño I y su esposa, Alfonso III y el infante Ramiro. La descripción más exhaustiva conservada de este espacio se debe a Ambrosio de Morales, quien en su viaje a Asturias y León la describe como una capilla chica, de techo bajo, repleta de sepulcros

ideológicos", en Modelos, intercambios y recepción artística (de las rutas marítimas a la navegación en red), Palma de Mallorca, 2008, pp. 37-47; E. CARRERO SANTAMARÍA, “La ciudad santa de Oviedo, un conjunto de iglesias para la memoria del rey", en Hortus Artium Medievalum, vol. 13/2, 2007, pp. 375-389.

49 A. DE MORALES, Viaje de Ambrosio de Morales a los reinos de León y Galicia y Principado de Asturias en 1572, Madrid, 1765, reed. Oviedo, 1971, pp. 86-93. Este espacio fue excavado en 1926, cuando ante la instalación de la calefacción, se encontraron ciertos vestigios que permitieron conocer arqueológicamente el panteón ovetense. Según Aurelio Llano aparecieron "restos de los sepulcros donde yacieron los reyes, cuatro basas de pilastras y otros indicios arquitectónicos". A. LLANO ROZA DE AMPUDIA, Bellezas de Asturias. De Oriente a Occidente, Oviedo, 1928, pp. 336-340.

${ }^{50}$ A pesar del interés del tema sobre el origen, desarrollo y expansión geográfica de los espacios occidentales de carácter funerario, no es este el lugar para tratarlo. Para más información sobre este aspecto ver: I. BANGO TORVISO, "El espacio para enterramientos privilegiados en la arquitectura medieval española" en Anuario del Departamento de Historia y Teoría del Arte (U.A.M.), Vol. IV, 1992. pp. 93-132; J.L. SENRA GABRIEL Y GALÁN, “Aproximación a los espacios litúrgico-funerarios en Castilla y León: pórticos y galileas", en Gesta, vol. 36 - no2, 1997, pp. 122-144; “Les massifs occidentaux des églises dans les royaumes du nord-ouest de la Péninsule Ibérique", en C. SAPIN, Avant-nefs et espaces d'accueil dans l'eglise entre le IV et le XII siècle. Actes du colloque international du CNRS Auxerre, 17-20 juin 1999, París, 2002, pp. 336-340; G. BOTO VARELA, "Aposentos de la memoria dinástica. Mudanza y estabailidad en los panteones regios leoneses (1157-1230)", en Anuario de Estudios Medievales, 42, 2, 2012, pp. 535-565. 
tan juntos que apenas se puede andar entre ellos, por lo que estaba normalmente cerrada al público ${ }^{51}$. De ellas destaca el cronista la de Alfonso II, que dice que está delante de la puerta, y que si tuvo alguna labor o letra, ya ha desaparecido; se desconoce cómo habría sido exactamente el sarcófago del Rey Casto, si bien a partir de descripciones como las del Obispo Pelayo, Tirso de Avilés y Luis de Carvallo, Raquel Alonso ha planteado la posibilidad de que se tratara de un sepulcro decorado con el emblema de la monarquía asturiana: una cruz anicónica ${ }^{52}$. No solo en su localización dentro del panteón destacaba la tumba de Alfonso II, sino también en sus celebraciones litúrgicas: según Morales tenía misa diaria en su capilla, dotada con siete capellanes, además de una solemne en enero que incluía procesión, y en época de Luis de Carvallo ya existía el aniversario en marzo que se ha conservado hasta nuestros días. En el siglo XVII esta celebración memorial en honor del Rey Casto incluía la presencia de la Justicia y el Regimiento de la ciudad en una procesión desde el ayuntamiento hasta la tumba donde se depositaban hachas de cera ${ }^{53}$.

Marañón de Espinosa añade una celebración litúrgica más a este espacio, dedicada a todos los miembros enterrados en él, cuando explica cómo el día de todos los difuntos las tumbas de los reyes eran cubiertas por un dosel de terciopelo negro y adornadas con candeleros de plata y velas encendidas, preparadas para recibir la bendición e incensión de las sepulturas. Este tipo de ceremonial recuerda levemente a otros, también de carácter regio que recogió Ambrosio de Morales. El primero de ellos tenía lugar en torno al sepulcro de Alfonso VI en el monasterio

\footnotetext{
${ }^{51}$ A. DE MORALES, Viage...pp. 86-93.

52 R. ALONSO ÁLVAREZ, "Patria uallata asperitate moncium. Pelayo de Oviedo, el archa de las reliquias y la creación de una topografía regia", en Locvs Amoenvs, 9, 2007-2008, pp. 17-29.

53 L. CARVALLO, Antigüedades y cosas memorables del Principado de Asturias, Salinas, 1977. pp. 199-201.
}

benedictino de Sahagún ${ }^{54}$. Allí, en medio de la capilla mayor estaban colocados los restos del rey ${ }^{55}$, y sobre su sepulcro una representación en madera "de gran tumba" donde aparece el rey armado y coronado rodeado por los escudos de armas de Castilla y León. Normalmente el sepulcro aparecía cubierto con un tapiz flamenco, expresamente realizado para él, si bien en fiestas principales le colocaban encima un dosel de brocado, y como sucedía en la capilla del Rey Casto, incensaban la tumba ${ }^{56}$. El otro ceremonial que se asemeja al ovetense tenía lugar en la capilla de los reyes de San Isidoro de León, si bien en este caso nada dice de cubrir las tumbas, aunque recoge cómo los lunes en la procesión de Difuntos, los canónigos entraban en la capilla real para decir un responso solemne e incensar los sepulcros ${ }^{57}$.

\section{La capilla funeraria del obispo Don Gutie- rre (+1389)}

Gutierre de Toledo fue, junto con Pelayo, uno de los obispos más destacados de la Asturias del Medievo. Nació en el entorno de 1330 en la parroquia de San Justo de Toledo, en el seno de una familia notable; pasó por diversos cargos de importancia en Castilla hasta que fue nombrado Obispo de Oviedo en 1377. De sus años como cabeza

${ }^{54}$ A. DE MORALES, Viage...pp. 34-39.

${ }^{55}$ Los restos de Alfonso VI fueron trasladados de su espacio original a los pies del templo a la capilla mayor por Sancho IV, para lo que tuvo que trasladar la tumba de doña Beatriz, colocada entonces en ese ábside. J.M. QUADRADO y F.J. PARCERISA, Recuerdos y Bellezas de España. Asturias y León, Madrid, 1855, facsímil, Oviedo, 1977, pp. 384-397.

56 A. DE MORALES, Viage...pp. 34-39. A Morales le parece demasiado excesiva esta incensación, diciendo que es algo que debe hacerse en vida pero que después de muerto debe reservarse únicamente a los Santos. Para una reconstrucción hipotética de las distintas fases por las que pasó la tumba de Alfonso VI ver J. BARRACHINA, "Hipótesis reconstructiva sobre la tumba de Alfonso VI", en VVAA, Alfonso VI y su legado. Actas del Congreso Internacional, Sahagún, 29 de octubre al 1 de noviembre de 2009, León, 2012, pp. 283-292.

${ }^{57}$ A. DE MORALES, Viage...pp. 41-53. 
de la cátedra ovetense destacan tres hitos: la contienda con el conde de Noreña, Alfonso Enriquez, la reforma de la diócesis de Asturias, y el inicio de las obras de la fábrica gótica de la catedral. Esta actividad se completó con la creación de una amplia serie de manuscritos que resultan imprescindibles en el archivo capitular del Salvador: El libro de los Privilegios (1382-1383), el libro de la Regla Colorada (1384), El libro de las Constituciones (1383) y el libro Becerro de san Salvador (a partir de 1385) ${ }^{58}$.

Su obispado se enmarca dentro de una sucesión de campañas constructivas que acabó por conformar la catedral gótica de San Salvador, ocupándose don Gutierre de la renovación del ábside sur de la capilla mayor de la catedral, una capilla en la que recibió sepultura ${ }^{59}$. Las obras comenzaron en 1379, tal como aparece en un documento conservado en el Archivo Capitular de Toledo y que fue publicado por Javier Conde y Francisco de Caso, acerca de la donación de un terreno situado tras la cabecera prerrománica del Salvador y que pertenecía a San Vicente de Oviedo, para la construcción del renovado espacio ${ }^{60}$. Dicha capilla, que según el documento debía ser "grande et onrrada", se situaba al sur de la cabecera prerrománica, donde anteriormente se encontraban las

58 F.J. FERNANDEZ CONDE, Gutierre de Toledo... pp. 258-276.

${ }^{59}$ F.J. FERNANDEZ CONDE, Gutierre de Toledo... pp. 251, y F. DE CASO, La Construcción...pp. 156-157. Los documentos indican que esperó a que la capilla estuviera completa para pedir formalmente al cabildo permiso para enterrarse en ella. Esta forma de actuar se repite en el caso del obispo Diego de Anaya en la catedral vieja de Salamanca, apenas unas décadas después de don Gutierre. J. YARZA LUACES, "La capilla funeraria hispana en torno a 1400 ", en en M. NUÑEZ, y E. PORTELA, La idea y el sentimiento de la muerte en la historia y en el arte de la edad media. Ciclo de conferencias celebrado del 1 al 5 de diciembre de 1986, Santiago de Compostela, 1988, pág. 90.

60 F.J. FERNANDEZ CONDE, Gutierre de Toledo... pp. 249-250, y 296-298.; F. DE CASO, Colección Documental sobre la Catedral de Oviedo I, Gijón, 1982. pp. 6-7; y La Construcción de la Catedral.... pp. 148-149. Si bien los dos coinciden en fecha y día, Javier Conde habla del 19 de marzo y Caso de mayo. capillas de San Bartolomé, San Simón y Judas, y San Andrés ${ }^{61}$. Las obras acabaron sólo cuatro años más tarde, cuando según observa Javier Fernández Conde, los documentos referidos a la dotación de la capilla hablan del espacio arquitectónico en pasado ${ }^{62}$.

La capilla de don Gutierre se proyectó como un espacio funerario individual destinado a la memoria del obispo, una tipología que por otro lado no era nueva en la Península Ibérica, y que se convirtió en el siglo XV casi en una obsesión entre la nobleza civil y eclesiástica ${ }^{63}$. Su descripción física no es fácil, ya que el entorno en el que fue construida, sustituyendo el antiguo ábside sur, desapareció con la reforma gótica, y la misma capilla fue derribada cuando se llevó a cabo la apertura de la girola en el siglo XVII. Francisco de Caso intenta reconstruir sus dimensiones a través de los documentos capitulares, concluyendo que en anchura se extendería desde la pared sur del ábside central hasta la entrada sur de la catedral de Alfonso II, y su profundidad sería la del ábside más el espacio de diez y seis pies que fue el donado por el monasterio de San Vicente. Se trataría de un espacio suficientemente

61 F.J. FERNANDEZ CONDE, Gutierre de Toledo... pág. 249.

${ }^{62}$ F.J. FERNANDEZ CONDE, Gutierre de Toledo... pág. 250 y F. DE CASO, La Construcción... pp. 148-149.

63 I. BANGO TORVISO, "El espacio para enterramientos privilegiados en la arquitectura medieval española" en Anuario del Departamento de Historia y Teoría del Arte (U.A.M.), Vol. IV, 1992.pp. 131-132. Bango Torviso expone que de forma espontánea, en diversas sedes, se crean espacios funerarios anejos al presbiterio pero que aparecen completamente separados de éste y en ningún caso incomodan al funcionamiento regular del templo. El primer ejemplo sería la capilla de la Trinidad en la catedral de Palma de Mallorca, y la de Rodrigo de Ávila, obispo de Plasencia en la iglesia de San Francisco de Ávila. Un ejemplo similar al de la capilla de don Gutierrre, algo posterior la encontramos en la figura del obispo Diego de Anaya, cuyo caso analiza Joaquín Yarza en "La capilla funeraria hispana en torno a 1400", en en M. NUÑEZ y E. PORTELA, La idea y el sentimiento de la muerte ... pp. 67-91; y Luis de Acuña, casi un siglo más tarde, en la catedral de Burgos. J. YARZA LUACES, Gil Siloé.El retablo de la Concepción en la capilla del obispo de Acuña, Burgos, 2000, pp.39-53. 
amplio para que fuera común la reunión de los canónigos, y la existencia de los tres altares sustituyendo las antiguas capillas prerrománicas ${ }^{64}$. Además de esto, contaba con dos puertas, una de las cuales era custodiada por los monjes de San Vicente, y la otra, que daría a la catedral era guardada por el obispo, y probablemente, contaría con una reja ${ }^{65}$. Por último, se iluminaba este espacio con tres vanos, que fueron cubiertos de vidrieras a principios del siglo XVI, con el resto de capillas del templo ${ }^{66}$. Este documento de cubrición de los vanos, publicado por Francisco de Caso, puede dar más pistas sobre el aspecto físico de la desaparecida capilla de san Salvador si se la compara con algunas de sus coetáneas. Solo unos años antes de la llegada de don Gutierre a la sede ovetense, se comenzaba en Toledo la construcción de la capilla de San Ildefonso, proyectada como enterramiento para el cardenal Gil Carrillo de Albornoz y que al igual que la del obispo de Toledo, don Pedro Tenorio, comenzada a construir en $1397^{67}$, forman parte de una serie hispánica de capillas ochavadas que tuvieron gran éxito en la Baja Edad Media como tipología funeraria ${ }^{68}$. Tal como expone Raquel Alonso, la dotación del edificio y la

${ }^{64}$ F. DE CASO, La Construcción de la Catedral... pp. 152-153.Los tres altares estaban dedicados a los santos que anteriormente constituían la advocación de las tres capillas: San Simón y Judas, San Bartolomé y San Andrés.

65 F. DE CASO, La Construcción de la Catedral... pág. 153.

66 F. DE CASO, La Construcción de la Catedral... pág. 156.

${ }^{67}$ A. FRANCO MATA, "El Arzobispo Pedro Tenorio: Vida y obra. Su capilla funeraria en el claustro de la catedral de Toledo", en VVAA, La idea y el sentimiento de la muerte en la historia y en el arte de la edad media (II). Ciclo de conferencias celebrado del 15 al 19 de abril de 1991, Santiago de Compostela, 1992, pp. 73-93. Cuenta también, como lo hará la capilla de don Gutierre con una importante donación de ornamentos litúrgicos y numerosos libros de temática variada.

${ }^{68}$ R. ALONSO ÁLVAREZ, “Las capillas funerarias en Asturias. Siglos XIV y XV" en Boletín del Instituto de Estudios Asturianos, año 50, no 147, 1996. pp.91-102. cantidad de enterramientos que albergaba hace pensar en una construcción de cierta envergadura y calidad, y el parentesco de don Gutierre en Toledo, aunque no garantice unas determinadas influencias artísticas hace pensar que, probablemente, el prelado ovetense estaría informado de las obras que se estaban llevando a cabo coetáneamente en la catedral de su ciudad de origen, de donde había sido racionero.

La dotación de la capilla funeraria del obispo fue considerable, comenzando por varias casas que tenía en propiedad en Valladolid, que se unen a otras posesiones para configurar tres capellanías perpetuas con un valor de cuatrocientos maravedís anua$\operatorname{les}^{69}$. Apenas dos meses después, la capilla recibe además una importante donación de elementos entre los que se encuentran libros, imágenes y otros enseres litúrgicos de los que destacan una virgen de alabastro, cuyo paradero se desconoce ${ }^{70}$. En octubre de 1382, con la dotación de otras dos capellanías se cierra el acuerdo final del enterramiento de don Gutierre con el Cabildo de la catedral. En 1384 la capilla ya contaba con siete capellanías, para entonces, el cabildo catedralicio estaba gravado con aniversarios perpetuos en la capilla a favor del obispo, sus padres, hermanos y resto de familia ${ }^{71}$. Alfonso Mara-

69 F.J. FERNANDEZ CONDE, Gutierre de Toledo... pág. 250

70 F.J. FERNANDEZ CONDE, Gutierre de Toledo... pág. 250. Fernandez Conde publicó algunas partes del documento, conservado en el Libro Becerro del archivo capitular de la catedral de Oviedo. De este ajuar funerario con el que don Gutierre dota a su capilla destacan: "una Biblia solempnissima litere bononiesis cupertam de tapeto rubeo cum clausuris de argento cum signis nostris", "unum Ordinarium modi novi litere bonionensis copertum tapeto virido cum clausuris de argento", "una ymago beate Marie de alabastro nescia cum suis aparatis et tribus leonunculis deauratis “. Además de una completa colección de libros litúrgicos, eucarísticos, jurídicos $\mathrm{y}$ de otras materias.

71 F.J. FERNANDEZ CONDE, Gutierre de Toledo... pp. 250-251. En 1386 aun realizará otra fundación de aniversario el 27 de abriil, dotado con los derechos de pesca del río Nalón que le había concedido el rey Juan I, y que debía ser realizado "según la del obispo don Fernán Alvarez". 
ñón de Espinosa, que escribe dos siglos después de la fundación del aniversario de don Gutierre, describe cómo sigue funcionando la memoria del obispo en el entorno de su capilla: aún contaba entonces, poco antes de su desaparición, con cuatro capellanes, dos mayores que realizaban cuatro misas semanales de forma alterna, y otros dos menores de los cuales uno realizaba dos misas por semana y otro una misa por semana. A esto, se añadía otra misa que había sido dotada por Juan de la Vandera ${ }^{72}$.

La capilla se destruyó al construirse la girola de la catedral de Oviedo en el siglo $\mathrm{XVII}^{73}$, por tanto, pocas son las noticias de historiadores que vieron el conjunto en pie. Solo Marañón de Espinosa, en Historia Eclesiástica de Asturias hace una breve referencia al enterramiento, "una sepultura bien labrada, con su figura de mármol"74. Por desgracia, nada queda del monumento funerario: cuando la capilla fue refundada con el nombre de San Ildefonso, los restos del obispo fueron trasladados a dicha capilla, y se encajaron en las paredes dos pequeñas inscripciones, casi imposibles de ver a simple vista.

"ESTA SANTA / IGLESIA HIÇO ESTA / CAPILLA AL SEÑOR DON GU / TIERRE DE TOLEDO OBISPO / QUE FUE DELLA / Y TRASLADO A ESTE / ENTIERRO SUS H / UESOS POR AVER DE / SECHO SU CAPILLA / PARA HACER TRASCORO".

La importancia de la capilla en la catedral ovetense resulta evidente cuando se comprueban algunos de los documentos conservados en su archivo. Rápidamente se convirtió en un importante centro de recepción de enterramientos y fundaciones de aniversarios hasta su destrucción en el

\footnotetext{
${ }^{72}$ A. MARAÑÓN DE ESPINOSA, Libro de los estatutos y constituciones...pp. 30b-31.

73 F.J. ERNANDEZ CONDE, Gutierre de Toledo... pág. 282

${ }^{74}$ A. MARAÑÓN DE ESPINOSA, Historia Eclesiástica de Asturias, Gijón, 1977. pág. 132.
}

XVII. Los documentos capitulares nos hablan de sepulturas ya desde mediados del siglo $\mathrm{XV}$ que a veces cuentan con una representación destacada a través de escudos de armas, e incluso enterramientos de arcosolio, como los que empezaban a plagar el claustro gótico, tanto de individuos como verdaderos panteones familiares ${ }^{75}$.

\section{El claustro}

En el caso de la catedral de Oviedo, como sucede con un elevado número del resto de catedrales españolas, a partir del siglo XIII los claustros pierden su función original a raíz de la secularización de los cabildos, que permitía a los miembros de los mismos habitar en sus propiedades, normalmente en las cercanías del conjunto catedralicio, pero fuera de él. Esta fue la causa del cambio de funcionalidad en los claustros catedralicios, cuando dejan de tener sentido estancias como dormitorio y cocina, que son sustituidas en un momento en que numerosos claustros hispánicos fueron rehechos en estilo gótico, por capillas funerarias. En muchas ocasiones, esos nuevos espacios claustrales fueron proyectados sin dependencias para el cabildo, salvo la sala capitular y utilizando ese espacio para el desarrollo de capillas funerarias, normalmente concentradas en una de sus pandas ${ }^{76}$. Este abandono del espacio funcional por parte del cabildo permitió a los claustros medievales generar una nueva función económicamente muy favorecedora, la funeraria.

Los enterramientos ocuparon el claustro desde arcosolios en los muros,

${ }^{75}$ F. DE CASO, La Construcción de la Catedral...pág. 156; Francisco de Caso transcribió varios documentos sobre enterramientos y fundaciones en la capilla de don Gutierre en F. DE CASO, Colección Documental sobre la Catedral de Oviedo I, Gijón, 1982; y Colección Documental sobre la Catedral de Oviedo II, Gijón, 1983. pp. 107-109.

${ }^{76}$ E. CARRERO SANTAMARÍA, "El claustro funerario en el medievo o los requisitos de una arquitectura de uso cementerial", en Liño. Revista de Historia del Arte, nำ12, 2006, pp. 31-43. 
a enterramientos de suelo y en los intercolumnios del jardín hasta la propia zona vegetal ${ }^{77}$. Si en un primer lugar los enterramientos se distribuyeron por espacios más bien arbitrarios, a partir de las catedrales de Salamanca y Burgos, la función funeraria será tan primordial respecto a las otras que en su construcción se generan lo que Christopher Welander llama sepulcros "ready-made", entrantes a la manera de arcosolios, generados en los muros internos del claustro que incluyen una decoración propia de estos entornos funerarios y que permitían la colocación de un sarcófago personalizado ${ }^{78}$.

Cuando parece que el claustro funerario no puede desarrollar más su nueva función, con estos espacios ya proyectados en plano, catedrales como la de Santo Domingo de la Calzada, en la Rioja, llegaron a romper el paño mural de esas estructuras en arcosolio para generar capillas funerarias de mayores dimensiones ${ }^{79}$. Con este ejemplo llegamos a otro pequeño capítulo dentro de los claustros funerarios, las capillas de diferente índole que se generan en los claustros, desde las salas capitulares utilizadas como enterramiento de abades y obispos, como sucedió en el caso de Santiago, a las capillas funerarias creadas

\footnotetext{
77 M.T. LÓPEZ DE GUEREÑO SANZ, “Santa Ma-
} ría de Huerta, panteón de la nobleza castellana", en De Arte, 6, 2007, pp. 37-56, en concreto pp. 40-41.

78 C. WELANDER, "The architecture of the cloister of Burgos catedral", en E. FERNIE y P. CROSSLEY (eds.), Medieval Architecture and its intellectual context. Studies in honour of Peter Kidson, London and Ronceverte, 1990, pp. 159-168. Según Welander, el primer claustro en funcionar como cementerio es el de Salamanca (c. 1178), seguido por los ciertencienses de La Espina y Santes Creus. 164. Una serie de ejemplos similares a este, con articulaciones murarias en lucillos dispuestos para recibir sepulturas los encontramos en la región del Rosellón, una tipología que Géraldine Mallet denominó los claustros-cementerios, G. MALLET, "Les cloîtrescimetières du Roussillon", en Cahiers de Fanjeaux, La mort et l'au-delà en France meridionale, 33, Toulouse, 1988, pp.417-434.

79 E. CARRERO SANTAMARÍA, “El claustro...", pág. 41. exprofeso como la del Arzobispo Pedro Tenorio en la catedral de Toledo ${ }^{80}$.

Dentro de las cuatro crujías del claustro siempre es preferida, y por tanto más costosa, aquella cuyo muro interno es compartido con la iglesia, por estar en contacto con el templo, especialmente hasta el siglo XIII cuando el acceso de los enterramientos al interior de las iglesias se generaliza. A pesar de esa predilección por una panda concreta, en algunos casos, como por ejemplo el de la catedral de Sigüenza, cada una de ellas fue asignada a un colectivo: caballeros y gentes de iglesia; canónigos, racioneros e hijosdalgo; familiares de los beneficiados de la iglesia; y por último, parientes, criados y extraños ${ }^{81}$. Estos claustros añadirán en su función funeraria, además de los monumentos y enterramientos de suelo, epígrafes incrustados en la pared reclamando oraciones por el alma de los fallecidos que no tendrían suficiente capacidad económica o rango social para contar con un verdadero enterramiento en claustro.

El caso de la catedral ovetense cuyo claustro fue renovado entre los siglos XIV y $\mathrm{XV}$ no es una excepción. En él se localizaron numerosos enterramientos, tanto en arcosolios, de los que Francisco de Caso documentó siete, como de suelo ${ }^{82}$. En cuanto a enterramientos de suelo, documentados en los libros

${ }^{80}$ A. FRANCO MATA, "El arzobispo Pedro Tenorio: vida y obra. Su capilla funeraria en el claustro de la catedral de Toledo", en VVAA, La idea y el sentimiento de la muerte en la historia y en el arte de la edad media (II), Ciclo de conferencias celebrado del 15 al 19 de abril de 1991, Santiago de Compostela, 1992, pp. 73-93.

${ }^{81}$ M.T. LÓPEZ DE GUEREÑO SANZ, “Santa María de Huerta...", pág. 46.

82 F. DE CASO, Francisco, La Construcción de la Catedral...pp.131-144. Los enterramientos de suelo se conocen tanto por la documentación como por las diversas lápidas que aparecieron en las excavaciones llevadas a cabo por Hevia y Buelta en los años cuarenta del siglo XX. J.M. FERNANDEZ BUELTA y V. HEVIA GRANDA, Nueva Fase de las Excavaciones del Oviedo Antiguo, BIDEA, no 10, 1950, pp. 119-159; Ruinas del Oviedo Primitivo. Historia y secuencias de unas excavaciones, Oviedo, 1984 (reed.). 
de kalendas de la catedral ${ }^{83}$, destaca por su amortización la panda norte, la más cercana a la iglesia y, especialmente a la Cámara Santa, y el entorno de la puerta de la sala capitular, así como el mismo capítulo. Es en este contexto en el que se explica el desarrollo de una liturgia funeraria claustral que se convierte en una de las más habituales en todas las catedrales hispánicas, aparece documentada en la catedral de León, de una manera muy similar a la descrita por Alfonso Marañón de Espinosa, e incluso recorre el claustro en la misma dirección que la ovetense antes de volver a entrar en la catedral ${ }^{84}$. Otro ejemplo de liturgia de difuntos en el entorno claustral es el de la Seu Vella de Lleida, de la cual, si bien no contamos con tanto detalle como en el caso ovetense, se conoce que al menos pasaban por el claustro en el curso de la procesión ${ }^{85}$.

${ }^{83}$ V.M. RODRIGUEZ VILLAR, Libro de la Regla del Cabildo (Kalendas I), Oviedo, 2001. En el Archivo de la Catedral de Oviedo Libro de Kalendas II, vol. I, Códice 44 y Libro de Kalendas II, vol. II, Códice 45.

${ }^{84}$ A. FRANCO MATA, “Claustro gótico. Itinerario para la liturgia", en VVAA, La catedral de León: Mil años de historia, León, 2002, pp. 195-231; A. FRANCO MATA, "El claustro de la catedral de León. Su significación en el contexto litúrgico y devocional", en YJ. ARZA LUACES, M.V. HERRAEZ, G.BOTO VARELA (coord.), Congreso internacional "La catedral de León en la Edad Media", actas 7-11/4/2003, 2004, pág. 265.

${ }^{85}$ F. CASTILLÓN CORTADA, "Liturgia...", pág. 229. El autor recoge las informaciones obtenidas en tres códices conservados en la catedral, datados entre el siglo XIV y el medieados del XVI, así como un manuscrito del XIX. Cuando transcribe las informaciones no concreta a qué pertenece cada relación. En concreto sobre la ceremonia claustral del día de todos los difuntos, "Omnes absoluciones dicantur in choro et illis finitis exeunt a choro et dicunt illa undecim dierum lune et feriam per claustra usque ad novem inclusive. Deinde tres absoluciones por domino Rmo. Petro de Rege, pro quo aniversarium in isto die ut supra. Postea dicunt illas duas relictas ad complendum illatum undecim feriarum et illis incipientibus exeunt per ianuam Filiorum et circundant ecclesia et redeunt per ianuam claustri regis. Et tenientes ad chorum ibi dicunt duodecim absoluciones por anima domini Petri de Sanabuja, quipus dictis, finitur officium cum requiescant in pace, amen. Et absoluciones domini Petri Sanahuia solvit actor manumissor dicti Sanhuia, qui est Samper unus de canonicis. Est notandum quod in isto secundo die defunctorum fiunt absoluciones generales pro sequentibus, quas solvit venerabilis procurador aniversariorum".

\section{La capilla mayor de la catedral de Oviedo como panteón episcopal}

La última estación de la procesión descrita por Alonso Marañón de Espinosa el día de difuntos tenía lugar en la capilla mayor de la catedral, así como, ante ella, al día siguiente se organizaba el ofertorio. Tras la muerte de don Gutierre de Toledo la fábrica catedralicia continuó su renovación gótica por el ábside central durante el episcopado del francés Guillermo de Verdemonte, quien a su muerte fue inhumado en él. A Guillermo de Verdemonte le siguieron en su nuevo espacio funerario otros siete obispos durante los siglos XV y XVI: Juan Arias del Villar, García Ramírez de Villaescusa, Diego de Muros, Jerónimo de Velasco, Juan de Yora, Gonzalo de Solórzano y Francisco de Orantes (fig. 4).

En doscientos años, nueve obispos fueron enterrados en el ábside de la catedral de San Salvador, si bien uno únicamente permaneció allí un corto periodo de tiempo, hasta ser trasladado al enterramiento de su elección. Otro de ellos, Juan de Ayora, no había realizado disposiciones testamentarias sobre su enterramiento. De los que conocemos sus mandas testamentarias, llevaron a cabo fundaciones de capellanías, aniversarios y misas por su memoria y las de sus familiares, que llegan a tener lugar incluso inmediatamente después de la misa mayor, como es el caso de Jerónimo de Velasco, lo que nos indica que el altar mayor debió de ser un lugar de considerable actividad memorial.

La cabecera era considerada como lugar de enterramiento de obispos al menos en el siglo XVI, tal y como nos muestran los casos de Jerónimo de Velasco, que quería enterrarse en el entorno de la Cámara Santa pero el cabildo le ofreció la capilla mayor por ser el mejor espacio de que disponían; el de Juan de Ayora, que tras fallecer sin disposiciones funerarias fue enterrado en la cabecera; y el de Gonzalo de Solórzano, cuyo cadáver permaneció tan solo unos días sepultado en la catedral, lo hace por 
disposición del cabildo también en la capilla mayor ${ }^{86}$.

Cuando comparamos esta especie de panteón episcopal que se genera en la catedral de san Salvador ${ }^{87}$ con otros plenamente organizados como es el de la catedral de León ${ }^{88}$, el ovetense da una impresión de cierto carácter aleatorio. Esto se debe a que no fue, según las noticias con las que contamos por ahora, conformado siguiendo unas directrices fijadas por una personalidad concreta, sino que sería más bien el resultado de los gustos de cada obispo como individuo, después de haber pedido permiso al cabildo, los que dan ese carácter de conjunto a los enterramientos de la capilla mayor.

${ }^{86}$ El obispo Gonzalo de Solórzano dejó en su testamento disposición de fundar una iglesia en Torralba con sus capellanes donde deseaba ser enterrado. Sin embargo, a su muerte sus disposiciones no fueron respetadas y se le enterró en la iglesia de Nuestra Señora de Noreña, de donde el cura de una parroquia en Langreo sustrajo su cadáver. Ante estas irregularidades, el cabildo decide enterrar sus restos temporalmente en la capilla mayor de la catedral a la espera de su traslado a Torralba. S. GARCÍA GONZÁLEZ, Arte y liturgia funeraria en la catedral de Oviedo. Los enterramientos episcopales, Tesina de licenciatura inédita, Universidad de Oviedo, 2011, pp. 67-68.

${ }^{87}$ F. CASO, La construcción de la catedral...pp. 195203. Francisco de Caso ya llamaba la atención sobre este carácter de la capilla mayor ovetense, como el lugar más solicitado para efectuar enterramientos de personajes de notable categoría, como lo son los obispos durante los últimos siglos de la Edad Media.

${ }^{88}$ R. SANCHEZ AMEIJEIRAS, "Monumenta et memoriae: the thirteenth-century episcopal panteón of León Cathedral", en E. VALDEZ DEL ALAMO y C. STAMATIS PENDERGAST, Memory and the Medieval Tomb, Cambridge, 2000, pp. 269-293. El caso del panteón episcopal leonés se expande más allá de la capilla mayor, una obra llevada acabo por un obispo en concreto, Martín Fernández, que buscaba reforzar el poder episcopal frente al del cabildo de la catedral conformando este panteón ya en el siglo XIII Un ejemplo semejante y contemporáneo al de León sería el de la abadía de Chaalis, A. MCGEE MORGANSTERN, "Liturgical and honorific implications of the placement of gothic wall tombs", en Hortus Artium Medievalium, vol. 10, 2004, pp. 81-96.

\section{CONCLUSIONES}

El Libro de los estatutos y constituciones de la Sancta Iglesia de Oviedo, con el ceremonial y kalendario de sus fiestas antiguas redactado por Alonso Marañón de Espinosa ha servido para conocer el tipo de ceremoniales que a principios de la Edad Moderna tenían lugar en la catedral de Oviedo, desde funerales específicos por la muerte de los obispos a tradiciones vinculadas con las ofrendas funerarias a las que puede rastrearse un origen mucho más antiguo.

Por otro lado, a través de la procesión del día de Todos los Difuntos se han recorrido los espacios funerarios privilegiados que la catedral de Oviedo albergó durante la Edad Media, algunos de los cuales solo conocemos a través de descripciones antiguas, constituyendo esta consueta una nueva fuente que ha permitido tanto la obtención de datos hasta ahora desconocidos, como la afirmación de otros que aparecían en otras fuentes antiguas.

Este tipo de fuente documental permite, no solo conocer el objeto en concreto, como serían en este caso las capillas y espacios funerarios, sino también el uso que el cabildo catedralicio hace de ellos al margen de su funcionalidad inherente como enterramiento. Permite visualizar como la catedral de Oviedo, al igual que el resto de sedes peninsulares, cambiaron notablemente tanto a raíz del concilio de Trento como de las sucesivas reformas arquitectónicas que sufrieron a lo largo de los siglos del Renacimiento y del Barroco, y que tan a menudo ocultan el aspecto que estos edificios pudieron tener en épocas anteriores. 


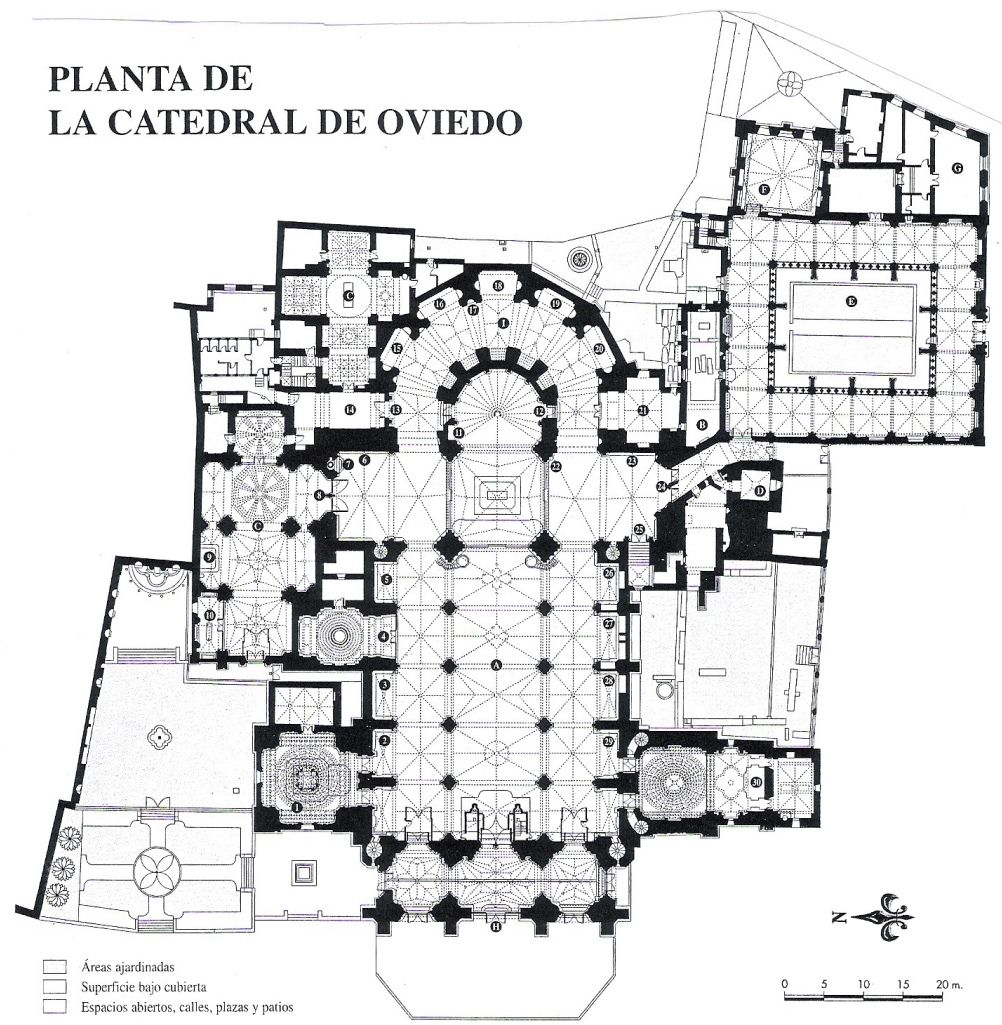

- Fig.1. Planta de la catedral de Oviedo, Cosme Cuenca y Jorge Hevia, 1997.

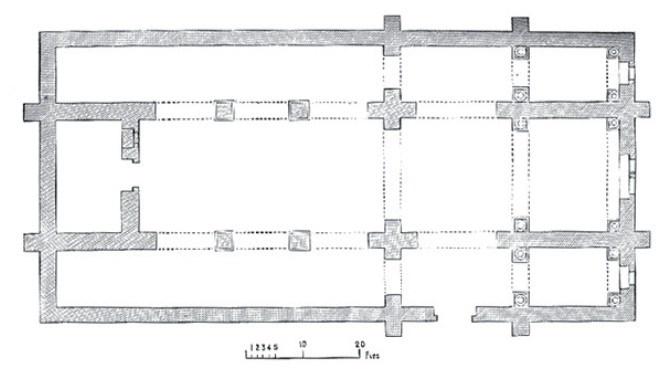

- Fig.2. Planta de la Basílica de Santa María del Rey Casto. Fortunato de Selgas, 1908.

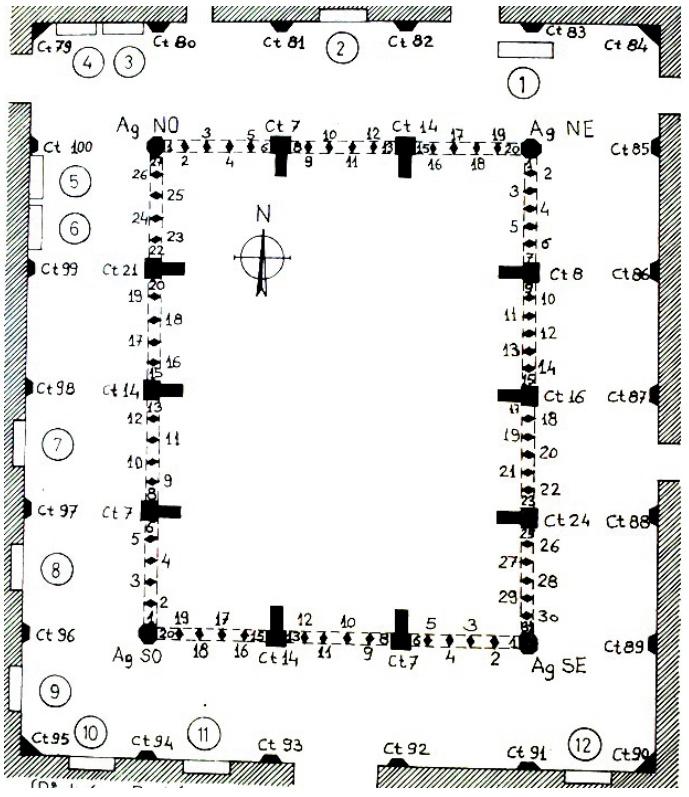

- Fig.3. Planta del claustro de la catedral de Oviedo. Francisco de Caso, 1981. 


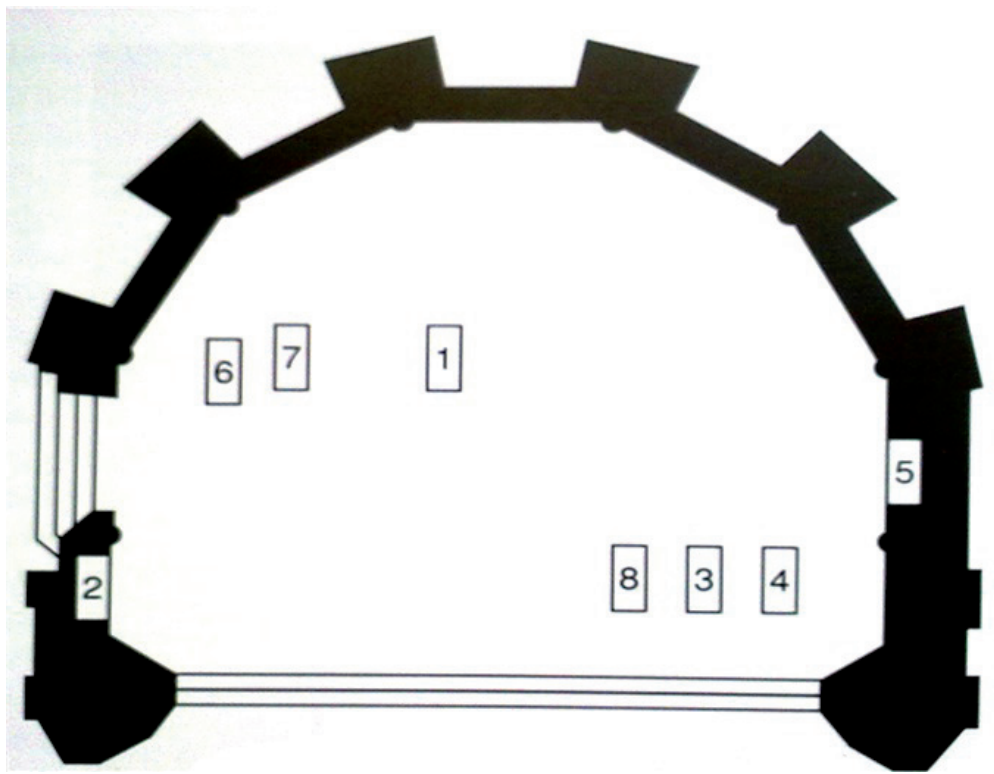

- Fig.4. Planta de la capilla mayor de la catedral de Oviedo. Hipótesis de localización de los enterramientos de obispos. Francisco de Caso, 1981. (1. Guillén de Verdemonte. 2. Juan Arias del Villar. 3. García Ramirez de Villaescusa. 4. Diego de Muros.5. Jerónimo de Velasco. 6. Juan de Ayora.

7. Gonzalo de Solórzano. 8. Francisco de Orantes)

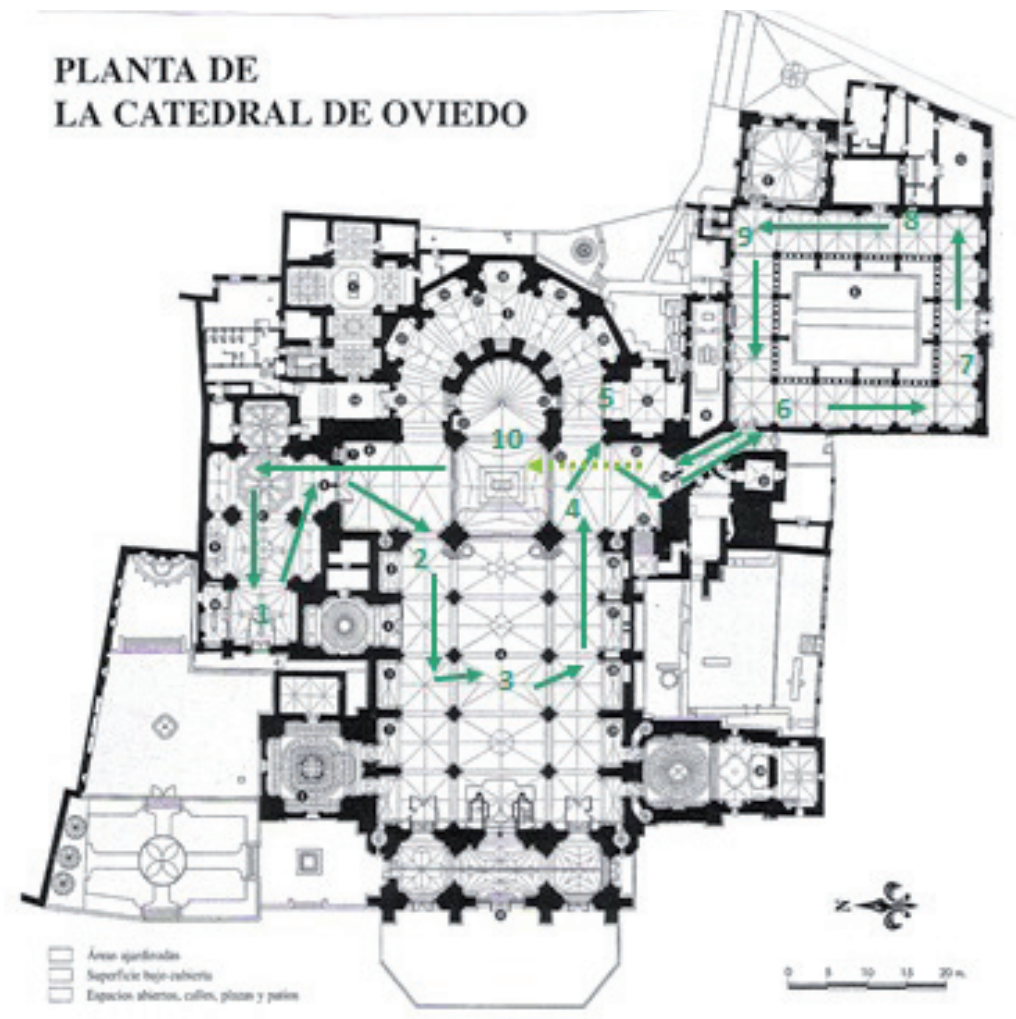

- Fig.5. Dibujo de Sonsoles García sobre planta de Cosme Cuenca y Jorge Hevia, 1997. El dibujo representa el recorrido procesional del día de Todos los Difuntos. El número representa cada estación. 